\title{
Water-conserving mining influencing factors identification and weight determination in northwest China
}

\author{
Limin Fan $^{1} \cdot$ Liqiang $\mathrm{Ma}^{1,2,3} \cdot$ Yihe $\mathrm{Yu}^{3} \cdot$ Shuokang $\mathrm{Wang}^{3} \cdot$ Yujun $\mathrm{Xu}^{3}$
}

Received: 14 June 2018/Revised: 23 October 2018/Accepted: 4 December 2018/Published online: 3 January 2019

(C) The Author(s) 2019

\begin{abstract}
Water-conserving mining is an effective way to alleviate the contradiction between fragile ecological environment and high-intensity coal mining in the arid and semi-arid region of northwest China. It needs to consider the engineering and geological conditions, hydrogeological conditions and mining methods of coal seams. From the three aspects, this paper systematically analyzes the influencing factors and establishes an identification model with multi-level structures. The model includes three primary factors (including the engineering and geological conditions, hydrogeological conditions and mining methods), nine secondary factors (including overlying strata thickness, aquiclude, mining parameters and etc.), sixteen third-tier factors (including the faults, aquiclude thickness and effective mining height and etc.) and twelve fourth-tier factors (including the fault throw exponent, aquiclude permeability and coal pillar sizes and etc.). On the basis, the analytic hierarchy process is used to build the judgment matrix and obtain the weight of each influencing factor. The results indicate that the overlying strata thickness, aquiclude and effective mining height are the most important factors among the primary factors of engineering and geological conditions, hydrogeological conditions and mining methods, respectively. The research results could provide theoretical references for the water-conserving mining of coal resources in northwest China.
\end{abstract}

Keywords Water-conserving mining $\cdot$ Influencing factors $\cdot$ Analytic hierarchy process $\cdot$ Judgment matrix $\cdot$ Weight

\section{Introduction}

The northwest region is China's major coal-production region (Gu 2015). During the 'Eleventh Five-Year Plan' period, 13 national key constructed large coal bases are mainly in Shanxi, Shaanxi, Inner Mongolia and Ningxia areas with fragile ecological environment and serious soil and water loss (Miao et al. 2009). Most coal seams in these

Liqiang Ma

ckma@cumt.edu.cn

1 Shaanxi Institute of Geo-Environment Monitoring, Xi'an 710054, China

2 School of Energy, Xi' an University of Science and Technology, Xi' an 710054, Shaanxi, China

3 School of Mines, China University of Mining and Technology, Xuzhou 221116, Jiangsu, China areas have large thickness and shallow burial depth. Therefore, large-scale and high-intensity coal mining could easily lead to water inflow and leakage in shallow strata, aggravate the fragile ecological environment and even bring catastrophic destruction (Zhang et al. 2017). To solve the contradiction between fragile ecological environment and high-intensity coal mining in northwest China, the concept of water-conserving mining has been put forward in academic circles (Fan 2005).

As an important part of green mining (Qian et al. 2007), the water-conserving mining was originally to solve the underground seepage during the mining process of Jurassic coal seams in northern Shaanxi. As the concept of green mining gradually enjoys popular support, it has been promoted and applied in northern China and Xinjiang areas and has achieved remarkable results (Wu 2014; Zhang et al. 2015). Through many years' theoretical researches and engineering practice, the water-conserving mining 
theory and technology system has initially formed in order to protect ecological water level (Wang et al. 2010; Fan 2017).

The above-mentioned researches have made important contributions in water-conserving mining in areas with fragile ecological environment. They have improved the theoretical basis of water-conserving mining, supplemented the technology system and broadened the concept of water-conserving mining. These researches also have pointed out the factors that must be considered during the water-conserving mining. Fan et al. (2016) has analyzed the relationship between groundwater level decline and high-intensity mining of coal seams. It has pointed out that the mining intensity is determined by the dimensions of working face, mining height and advance velocity and etc. Huang (2017) holds that mining depth, mining height, overlying strata thickness and properties determine the development of upward and downward cracks of waterresisting rocks. Miao et al. (2007) has studied the waterresisting capability of composite water-resisting key layer from the aspect of strata combination. Wang et al. (2010) has divided the spatial relations between the coal and the aquifer (aquifuge) based on overlying strata thickness, mining height, aquifer thickness, aquifuge thickness, water-physical properties and etc. Ma et al. (2013) has divided the aquifers based on loose aquifer thickness, permeability coefficients and supply patterns. In addition, the empirical calculation formula of height of water flowing fractured zone has been given based on the mining height.

The above-mentioned researches have analyzed the influencing factors of water-conserving mining from different perspectives. Due to various research starting points, they have different emphases. This paper divides the influencing factors into engineering and geological conditions, hydrogeological conditions and mining methods. Taking Yulin-Shenmu mining area as the research background, this paper analyzes the influencing factors from the above three aspects. Then the analytic hierarchy process is used to calculate the weight of each factor. The results could provide references for the water-conserving mining of coal mines in northwest China.

\section{Multilevel structural model}

The influencing factors of water-conserving mining are analyzed from the aspects of engineering and geological conditions, hydrogeological conditions and mining methods. A four-level structure model has been established.

\subsection{Engineering and geological conditions}

\subsubsection{Overlying strata thickness}

The relative relation between the overlying strata thickness and the development height of water flowing fractured zone directly determines whether water resource losses will occur due to mining (Zhang and Peng 2005).

\subsubsection{Lithology of overlying strata}

The soft rock strata have better water-resisting effects, such as clay, the flexible rock with high shale content, strata with good consolidation and undeveloped cracks and karst (Chai and Li 2014).

\subsubsection{Physical and mechanical properties}

The physical and mechanical properties mainly refer to the rock's bulk density and strength. When the coal seam roof has certain intensity, the fractured blocks after caving could more easily interact and form the structure with certain bearing capacity, thus reducing the deformation and failure degree of the overlying strata and the final development height of the water flowing fractured zone.

\subsubsection{Strata combination}

The water-resisting strata composed of hard and soft strata are helpful to resist the integrative action of mine pressure and water pressure and could be key water-resisting strata (Miao et al. 2007).

\subsubsection{Geological structure}

\section{(1) The fault}

The faults could damage the integrity of the rock and influence the mechanical properties. The faults in overburden make the development height of the water flowing fractured zone larger than that in normal areas, which is not good for safety underwater mining (Huang et al. 2009). Generally, the fault density, length and throw index are needed to comprehensively describe the fault (Meng et al. 2000).

The fault density $q_{1}$ refers to the number of faults in the unit area.

$q_{1}=n_{1} / s$, number $/ \mathrm{km}^{2}$

where $n_{1}$ refers to the number of faults in the block, and $s$ refers to the area of the block, $\mathrm{m}^{2}$.

The fault length $q_{2}$ refers to the total length of the faults in the unit area of the block. 
$q_{2}=\sum_{i=1}^{n} l_{i} / s$

where $l_{i}$ refers to the length of the $i$ th fault, $\mathrm{m}$. The fault throw index $q_{3}$ refers to the ratio of fault throw $h$ to the mining height of the coal seam. To better discriminate the index, the logarithmic function of coal seam mining height could be used to amend the $q_{3}$.

$q_{3}=\frac{1}{n_{1}} \sum_{i=1}^{n} \frac{h_{i}}{m} \times \frac{1}{\ln (m+1)}$

where $h_{i}$ refers to the fault throw, $\mathrm{m}$, and $m$ refers to the mining height of the coal seam, $\mathrm{m}$.

(2) The folds

The folds could affect strata movement to certain extent (Sun et al. 2007). The quantitative index of fold development degree could be described by deformation coefficient, that is the fold section coefficient and fold plane coefficient (Yuan et al. 1992).

\subsection{Hydrogeological conditions}

\subsubsection{The aquifers}

\section{(1) Recharge}

If the recharge source is meteoric water or surface runoff, the recharge rate will change with the season and climate.

\section{(2) Thickness}

The aquifer thickness is directly related to storage capacity and thus influence the classification of water abundance (Ma et al. 2013).

\section{(3) Permeability coefficient}

As the permeability coefficient increases, the storage capacity and receiving capacity will enhance (Ma et al. 2013). The permeability coefficient $k$ is also called hydraulic conductivity. It is defined as the unit flow under a unit hydraulic gradient.

$K=k \frac{\gamma}{\mu}$

where $k$ refers to the permeability of rocks, md; $\gamma$ refers to the bulk density of water, $\mathrm{kN} / \mathrm{m}^{3} ; \mu$ refers to the dynamic viscosity of the water, $\mathrm{N} \mathrm{s} / \mathrm{m}^{2}$.

\section{(4) Groundwater depth}

The shallow groundwater has a significant impact on ground ecosystem (Ma et al. 2017; Wang et al. 2013) and is the primary objects of protection during the water-conserving mining.
(5) Water-level difference of vertically adjacent aquifers

The vertically adjacent multilevel aquifers have some hydraulic connections and the water level is close. The water-level changes during the mining could lead to cross flow between adjacent aquifers ( $\mathrm{Li}$ et al. 2017a, b).

\subsubsection{The aquifuge}

\section{(1) Thickness}

The effective thickness of the aquifuge could directly affect the water-resisting capacity (Ma et al. 2015).

\section{(2) Horizon}

The greater the distance between the aquifuge and the coal seam, the smaller the influence of mining will be, and the water-resisting capacity could be kept maximum.

\section{(3) Water-physical properties}

The water-physical properties of the aquifuge mainly include the permeability coefficient, expansibility and water sensitivity. The rock strata with smaller permeability coefficient tend to have better water-resisting capacity. The strata with bigger expansibility are prone to swelling after absorbing water, which is helpful for reclosing of rock fractures and recovery of water-resisting capacity ( $\mathrm{Li}$ et al. 2017a, b). When the rock has strong water sensitivity, its strength will be reduced and tend to be muddy after being soaked with water. The fractures in rock strata could easily close and the water-resisting capacity increases greatly.

\subsection{Mining methods}

\subsubsection{Mining methods}

The selection of mining methods could affect the final development height of the water flowing fractured zone (Kang 1998). Under the same conditions as others, the slice mining could effectively reduce the development height compared with the method of mining all height at one time (Fan et al. 2015).

\subsubsection{Mining parameters}

\section{(1) The effective mining height}

The mining height is the most direct and important influencing factor of the development height of the water flowing fractured zone. At present, the widely used empirical formula is fixed by taking the height of the water flowing fractured zone as the parameter (Shi et al. 2012). 
Table 1 Evaluation table of the relative weight

\begin{tabular}{|c|c|c|c|c|c|}
\hline $\begin{array}{l}\text { Engineering-geological } \\
\text { conditions } B 1\end{array}$ & $\begin{array}{l}\text { Thickness } \\
C 1\end{array}$ & $\begin{array}{l}\text { Lithology } \\
C 2\end{array}$ & $\begin{array}{l}\text { Physical and mechanical } \\
\text { properties } C 3\end{array}$ & $\begin{array}{l}\text { Strata combination } \\
C 4\end{array}$ & $\begin{array}{l}\text { Geological structure } \\
\text { C5 }\end{array}$ \\
\hline Thickness $C 1$ & 1 & 1 & 1 & 3 & 5 \\
\hline Lithology $C 2$ & 1 & 1 & 1 & 3 & 5 \\
\hline $\begin{array}{l}\text { Physical and mechanical } \\
\text { properties } C 3\end{array}$ & 1 & 1 & 1 & 3 & 5 \\
\hline Strata combination $C 4$ & $1 / 3$ & $1 / 3$ & $1 / 3$ & 1 & 5 \\
\hline Geological structure $C 5$ & $1 / 5$ & $1 / 5$ & $1 / 5$ & $1 / 5$ & 1 \\
\hline
\end{tabular}

\section{(2) Mining depth}

As the mining depth increases, the ground pressure also increases, thus making the overburden movement scale increase and promoting the development of water flowing fractured zone (Shi et al. 2012).

\section{(3) Advance velocity}

The integral subsidence of the overburden is nearly proportional to the advance velocity of the working face. The faster the advance velocity, the more gently the subsidence basin will be. The maximum dynamic deformation of overburden movement will decrease as the working face advances (Ma et al. 2014).

(4) Inclination of the working face

During the inclined mining, the roof will slip along the inclination after caving, thus making the height of the water flowing fractured zone increase significantly (Li et al. 2015).

\section{(5) Working face dimensions}

The height of the overburden water flowing fractured zone will increase as the working face advances. After reaching the full mining, the water flowing fractured zone will stop upward developing (Ma et al. 2011).

(6) The stability of coal pillars

The stability of coal pillars could directly affect the movement and deformation of overburden supported and controlled by coal pillars. The coal pillar stability is determined by its sizes and mechanical properties of the coal.

\section{Weight of influencing factors}

\subsection{Analytic hierarchy process}

The analytic hierarchy process (AHP) is a multi-criteria decision method involving both quantitative and qualitative analysis (Wu et al. 2011). It could be used to calculate the weight of influencing factors of water-conserving mining. The specific steps are as follows:

(1) The determination of influencing factors

$U=\left\{u_{1}, u_{2}, \ldots, u_{n}\right\}$

\section{(2) Judgement matrix construction}

With the 1-9 and their reciprocals scale method, the relative importance of each element could be reflected by fixing the values of the judgement matrix elements. The specific values in line with the actual mining conditions could be used to show the importance of factor comparison. The specific values should be fixed by the corresponding factors of the judgment matrix, that is $S=\left(u_{i j}\right)_{n \times n}$. Table 1 shows the relative weight evaluation of sub-factors of primary factors of engineering and geological conditions by an expert. The judgment matrix is also obtained.

$S_{\mathrm{B} 1}=\left|\begin{array}{ccccc}1 & 1 & 1 & 3 & 5 \\ 1 & 1 & 1 & 3 & 5 \\ 1 & 1 & 1 & 3 & 5 \\ 1 / 3 & 1 / 3 & 1 / 3 & 1 & 5 \\ 1 / 5 & 1 / 5 & 1 / 5 & 1 / 5 & 1\end{array}\right|$

\section{(3) Judgment matrix calculation}

The weight coefficients could be determined by calculating the largest eigenvalue of $\mathrm{S} \lambda_{\max }$ and the corresponding eigenvector $\boldsymbol{A}$.

The largest eigenvalue $\lambda_{\max }$ of SB1 is 5.1544 and the corresponding eigenvector $\boldsymbol{A}=(0.2763,0.2762,0.2762$, $0.1238,0.0470)$.

(4) Consistency check

The consistency indicator $C I=\frac{\lambda_{\max }-n}{n-1}$ and the random consistency index $C R=\frac{C I}{R I}$ are obtained, where $R I$ is the average random index. When $C R<0.1$, the sorting of the judgment matrix elements has consistency, that is, the weight distribution is reasonable. When $C R \geq 0.10$, the 


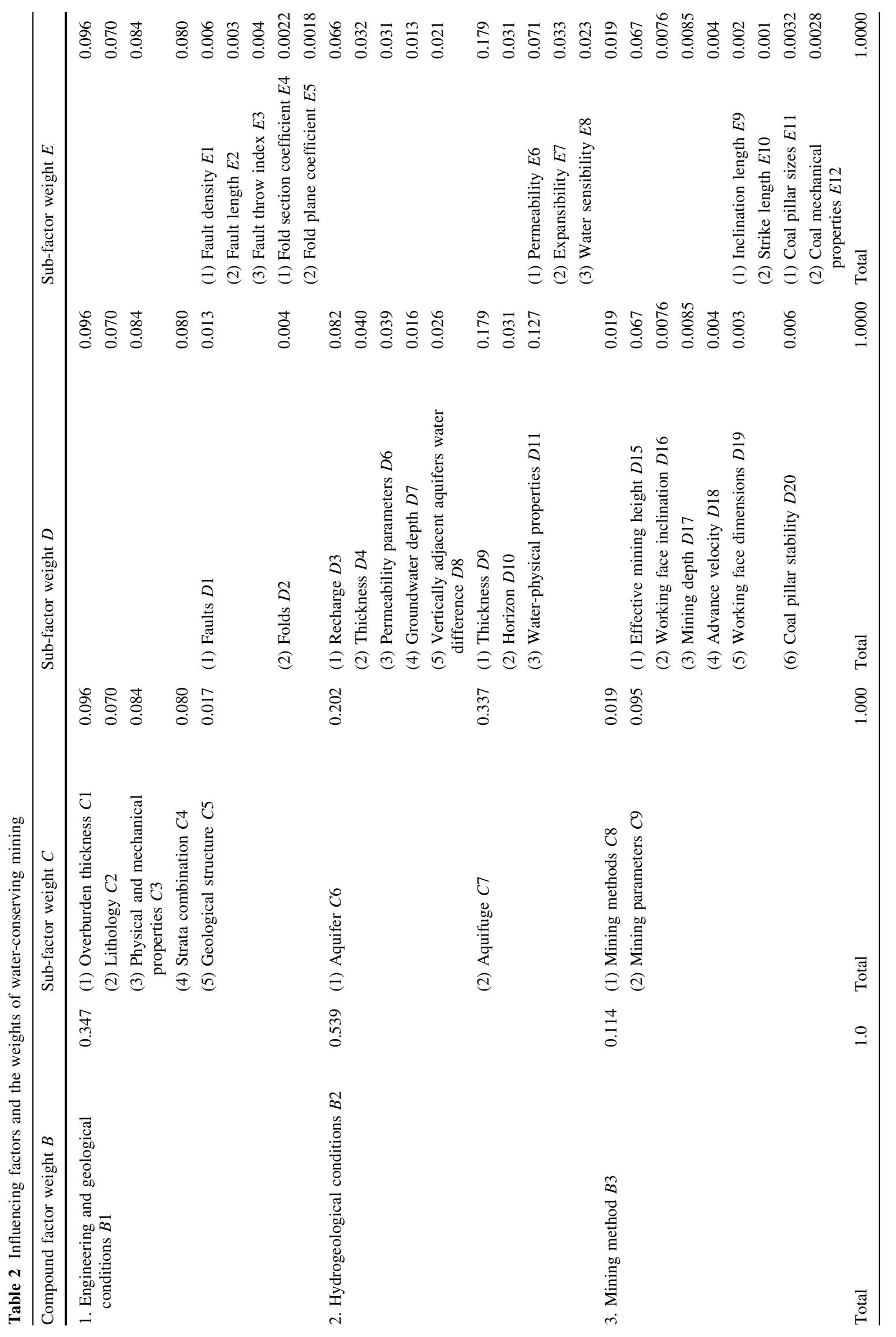


sorting and values of elements should be adjusted and the weights need to be redistributed.

The $C I$ of $S_{\mathrm{B} 1}$ is 0.0386 . The average $R I$ of fifth-order matrix is 1.11 (Saaty and Ozdemir 2003). Then $C R=$ $0.0386 / 1.11=0.0348<0.10$, indicating that the weight distribution is reasonable. The weight of engineering and geological conditions in three primary factors is 0.347 . Then $0.347 * \boldsymbol{A}=(0.0959, \quad 0.0959, \quad 0.0959, \quad 0.0429$, 0.0164), which is the final weight of the five secondary factors among the primary factors given by the expert.

\subsection{Weight calculation}

Many experts and scholars engaged in water-conserving mining have been invited to evaluate the importance of influencing factors at all levels. The AHP is used to analyze and calculate their weights. Table 2 shows the average values of weights of the influencing factors.

(1) Among the three primary influencing factors B1 (engineering and geological conditions), B2 (hydrogeological conditions) and $B 3$ (mining methods), $B 2$ is the most important, followed by $B 1$ and $B 3$.

(2) Among the secondary factors of $B 1$ (engineering and geological conditions), C5 (geological structure) has the minimum weight, and the weights of $C 1$ (thickness), C2 (lithology), C3 (physical and mechanical properties) and $C 4$ (strata combination) are actually close.

(3) Among the secondary factors of B2 (hydrogeological conditions), the weight of the aquifuge $C 7$ is larger than the aquifer $C 8$. Among the third-tier factors of $C 7$, the thickness $D 9$ has the maximum weight.

(4) Among the secondary factors of mining methods $B 3$, the weight of the effective mining D15 is obviously bigger than other factors, which is consistent with the result obtained by the traditional height empirical formula of the water flowing fractured zone, which chooses mining height as a parameter.

\section{Discussions}

Some influencing factors of water-conserving mining could be described quantitatively, such as the overburden thickness, while some factors could only be described in qualitative. While some factors could only be described in qualitative, such as strata combination. In the following studies, the fuzzy mathematical method will be used to provide normalized data for those indexes which are difficult to describe quantitatively. Then the objective weighting methods will be combined to provide more scientific weight distribution of water-conserving mining influencing factors.

\section{Conclusions}

(1) A four-level structure model of water-conserving mining has been established. The model includes three primary factors (engineering and geological conditions, hydrogeological conditions and mining methods), nine secondary factors such as the overburden thickness, sixteen third-tier factors such as the water-physical properties of the aquiclude and twelve fourth-layer factors such as coal pillar sizes.

(2) The analytic hierarchy process (AHP) is used to construct the judgement matrix and the weight of each influencing factor has been obtained.

(3) The overburden thickness, the aquiclude and the mining methods are the most important secondary factors among the engineering and geological conditions, hydrogeological conditions and mining methods, respectively.

Acknowledgements This paper was supported by the National Key Basic Research Program of China (973 Program) (grant number 2015CB251600), the National Natural Science Foundation of China (51874280), the Open Project of Key Laboratory of Mine Geological Hazards Mechanism and Control (grant number KF2017-02) and the Priority Academic Program Development of Jiangsu Higher Education Institutions.

Open Access This article is distributed under the terms of the Creative Commons Attribution 4.0 International License (http://crea tivecommons.org/licenses/by/4.0/), which permits unrestricted use, distribution, and reproduction in any medium, provided you give appropriate credit to the original author(s) and the source, provide a link to the Creative Commons license, and indicate if changes were made.

\section{References}

Chai HC, Li WP (2014) Analysis of development mechanism of water transmitting fractured zone mining approaching to weathered and oxidized zone. Chin J Rock Mech Eng 33(7):1319-1328

Fan LM (2005) Discussing on coal mining under water-containing condition. Coal Geol Explor 33(5):50-53

Fan LM (2017) Scientific connatation of water-preserved mining. J China Coal Soc 42(1):27-35

Fan LM, Ma XD, Ji RJ (2015) Progress in engineering practice of water-preserved coal mining in western eco-environment frangible area. J China Coal Soc 40(8):1711-1717

Fan LM, Xiang MX, Peng J, Li C, Li YH, Wu BY, Bian HY, Gao S, Qiao XY (2016) Groundwater response to intensive mining in ecologically fragile area. J China Coal Soc 41(11):2672-2678

Gu DD (2015) Theory framework and technological system of coal mine underground reservoir. J China Coal Soc 40(2):239-246

Huang QX (2017) Research on roof control water conservation mining in shallow seam. J China Coal Soc 42(1):50-55 
Huang BX, Liu CY, Xu JL (2009) Effect of little fault in working face on water conducted fissure height. J China Coal Soc 34(10):1316-1321

Kang YH (1998) Influence of coal mining method change on the development law of water conducting fracture zone. J China Coal Soc 23(3):262-266

Li ZH, Xu YC, Li LF, Zhai CZ (2015) Forecast of the height of water flowing fractured zone based on BP neural networks. J Min Saf Eng 32(6):905-910

Li T, Wang SJ, Han L, Gao Y (2017a) Reasonable thickness of protected loess under loose aquifer in ecologically fragile mining area. J China Coal Soc 42(1):98-105

Li WP, Wang QQ, Li XQ (2017b) Reconstruction of aquifuge-the engineering geological study of $\mathrm{N}_{2}$ laterite located in key aquifuge concerning coal mining with water protection in northwest China. J China Coal Soc 42(1):88-97

Ma LQ, Zhang DS, Dong ZZ (2011) Evolution mechanism and process of aquiclude fissures. J Min Saf Eng 28(3):340-344

Ma LQ, Du X, Wang F, Liang JM (2013) Water-preserved mining technology for shallow buried coal seam in ecologicallyvulnerable coalfield: a case study in the Shen Dong coal field of China. Disaster Adv 6(S5):268-278

Ma LQ, Sun H, Wang F, Li JM, Jin ZY, Zhang W (2014) Analysis of the ground water level change of aquifer-protective mining in longwall coalface for shallow seam. J Min Saf Eng 31(2):232-235

Ma LQ, Jin ZY, Liang JM, Sun H, Zhang DS, Li P (2015) Simulation of water resource loss in short-distance coal seams disturbed by repeated mining. Environ Earth Sci 74(7):5653-5662

Ma XD, Fan LM, Yan G, Li WL (2017) Vegetation responses to groundwater level change in mining area. J China Coal Soc 42(1):44-49

Meng XR, Xu YY, Liu HY (2000) Classification standard and quantitative study of hard coal seam. J China Coal Soc 25(04):348-351

Miao XX, Chen RH, Bai HB (2007) Fundamental concepts and mechanical analysis of water-resisting key strata in waterpreserved mining. J China Coal Soc 32(6):561-564
Miao XX, Wang A, Sun YJ, Wang LG, Pu H (2009) Research on basic theory of mining with water resources protection and its application to arid and semi-arid mining areas. Chin J Rock Mechan Eng 28(2):217-227

Qian MG, Miao XX, Xu JL (2007) Green mining of coal resources harmonizing with environment. J China Coal Soc 32(1):1-7

Saaty TL, Ozdemir MS (2003) Why the magic number seven plus or minus two. Math Comput Model 38(3):233-244

Shi LQ, Xin HQ, Zhai PH, Li SC, Liu TB, Yan Y, Wei WX (2012) Calculating the height of water flowing fracture zone in deep mining. J China Univ Min Technol 41(1):37-41

Sun XY, Xia YC, Bai HM (2007) Numerical simulation of control of fold structures on mining subsidence. J China Coal Soc 32(5):490-493

Wang SM, Huang QX, Fan LM, Yang ZY, Shen T (2010) Study on overburden aquiclude and water protection mining regionazation in the ecological fragile mining area. J China Coal Soc 35(1):7-14

Wang L, Mu Y, Zhang QF, Zhang XC (2013) Groundwater use by plants in a semi-arid coal-mining area at the Mu Us Desert frontier. Environ Earth Sci 69(3):1015-1024

Wu Q (2014) Progress, problems and prospects of prevention and control technology of mine water and reutilization in China. J China Coal Soc 39(5):795-805

Wu Q, Fan ZL, Liu SQ, Zhang YW, Sun WJ (2011) Water-richness evaluation method of water-filled aquifer based on the principle of information fusion with GIS: water-richness index method. J China Coal Soc 36(7):1124-1128

Yuan CF, Zhang ZS, Zhang GD (1992) Discussion and application of fold deformation coefficient. J China Coal Soc 17(3):11-18

Zhang JC, Peng SP (2005) Water inrush and environmental impact of shallow seam mining. Environ Geol 48(8):1068-1076

Zhang DS, Liu HL, Fan GW, Wang XF (2015) Connotation and prospection on scientific mining of large Xinjiang coal base. J Min Saf Eng 32(1):1-6

Zhang DS, Li WP, Lai XP, Fan GW, Liu WQ (2017) Development on basic theory of water protection during coal mining in northwest China. J China Coal Soc 42(1):36-43 